\title{
nature
}

\section{A significant time for Europe}

After languishing in recent years, the vision of a research community operating effectively at a European level is being actively pursued. Larger member states should give it their support.

E uropean research commissioner Philippe Busquin has a dream: European scientists being free to work in labs of their choice from Sicily to Scotland, Latvia to Lisbon, being eligible for funding from any European research agency, communicating with colleagues all over the continent via high-speed research networks, and their intellectual property being protected by an affordable European patent.

This vision has long been held by the more Europhile members of the research community. Now, and not before time, the European Commission and national research ministers are beginning to rise to it, in the form of a European Research Area. Indeed, it is taking shape earlier than expected. The European science ministers' unanimous approval last week of the 'Resolution on establishing a European area of research and innovation' calls on the 15 member countries of the European Union (EU) to make it a reality without delay (see page 873).

Busquin is driven by the unarguable fact that Europe's political structure puts the continent's research community at a fundamental disadvantage compared with Japan and, especially, the United States. His concept of a cross-frontier European research space is strongly supported - in order of increasing financial clout - by the European Science Foundation, by the enthusiastic president of the European council of research ministers, Portugal's science minister José Mariano Gago, and by the heads of Europe's national research funding agencies ('EUROHORCs'). Gago and Busquin have entered the European stage at exactly the right moment; the climate for research is arguably better now than for a considerable time. Science has visibly moved up the European agenda, a fact that became palpable during the Lisbon summit in the spring. In the wake of such favourable omens and of the newly achieved power balance between the European Commission and the Council of Ministers, true reform of the European research landscape seems possible.

But Busquin knows that he can achieve little without the support of the member states, and that his role must also be that of a persuader and catalyst. A skilful communicator, he is seizing the opportunity provided by the new open-mindedness of many government heads towards considering a joint European research policy.

But how, in concrete terms, would a young scientist benefit from the European Research Area? Most important, it would become a lot easier to gain experience in, and import skills into, any European country. At long last, mobile researchers would be relieved from a series of restrictions, such as work permits, incompatible university qualifications and complications with taxation and social security.

That will be no mean political feat. More controversy is likely to be stirred, however, by the science ministers' calls on the EU member states to progressively open their national research programmes to non-national research projects. Many believe the latter to be the crucial point with regard to true Europeanization of research. Undoubtedly, it would add a sound European dimension to many research projects, and provide them with the critical mass, if two or more national agencies were to be involved. Voluntary multilateral cooperative agreements between national agencies and research councils could be a first step in this direction, provided they agree on the necessary modification of their legal statutes and area of responsibility. It remains to be seen whether the national agencies, particularly those in the large member countries, are prepared for such a move, or whether fear of having to give away some of their cake will prevail.

Gago's enthusiasm has been prominent and based on realities. Encouragingly, at last week's ministerial council meeting, his successor Roger-Gérard Schwartzenberg, the new French science minister, firmly promised to pursue the work begun by Gago and Busquin. The success of the European Research Area undoubtedly depends on his commitment, as part of the French presidency of the European Union which starts next month, and on deserved backing from Germany and the United Kingdom.

\section{Welcome Nature Immunology}

Next week sees the birth of a new Nature journal.

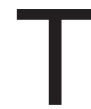
here are six monthly journals that carry the Nature name. The evidence suggests that all have managed to establish for themselves significant areas of top-quality publishing territory. That takes insight, enthusiasm and unrelenting effort by all involved.

The launch of the seventh Nature journal, Nature Immunology, has required no less. Readers will be able to judge the results for themselves on 28 June, when the first issue (dated July) goes live on the web at http://immunol.nature.com. As much as any other biological discipline, immunology is not only thriving but also being greatly stimulated by new developments elsewhere: genomics, informatic technologies such as microarrays, and, increasingly, computer modelling. And yet tackling the fundamental questions about the human immune system is as intellectually challenging as ever. The new journal is well set to convey this sense of excitement and to be at the forefront of such developments.
Nature's enthusiasm for publishing superb immunology will continue unabated: we wish to publish papers that are outstanding in their fundamental significance and broad interest, conveying their significance beyond the immunology community. The editorial relationship between the new journal and Nature itself is no different from that of the others. Publishing decisions are made by Nature Immunology's own staff on the basis of referees' comments: there is no consultation with Nature on individual papers, nor vice versa. In that sense the journals are independent. However, if Nature decides that an excellent paper lacks the broader significance we seek but would still be outstanding within the field of immunology, we will offer to the authors to pass the referees' comments on to Nature Immunology so as to save the authors effort and time.

Welcome to a significant new development for immunologists! 